\title{
EFFECT OF PULMONARY REHABILITATION PROGRAMME ON PATIENTS OF STABLE CHRONIC OBSTRUCTIVE PULMONARY DISEASE
}

Surya Kant, Rakesh Kumar, Tariq Mahmood, Alok Chandra, A. K. Verma, Ravi Bhaskar,

1. Prof \& Head, Department of Pulmonary Medicine, King George's Medical University, Lucknow.

2. Junior Resident-III, Department of Pulmonary Medicine, MLN Medical College, Allahabad.

3. Assistant Professor, Department of Pulmonary Medicine, MLN Medical College, Allahabad.

4. Assistant Professor, Department of Pulmonary Medicine, MLN Medical College, Allahabad

5. Assistant Professor, Department of Pulmonary Medicine, King George's Medical University, Lucknow.

6. Senior Resident, Department of Pulmonary Medicine, King George's Medical University, Lucknow.

\section{CORRESPONDING AUTHOR}

Dr. Surya Kant

Prof. \& Head, Department of Pulmonary Medicine,

King George's Medical University, Lucknow.

E-mail: pulmedkgmu@gmail.com

Ph: 00919415082119.

ABSTRACT: BACKGROUND: Chronic Obstructive Pulmonary Disease (COPD) is the most common chronic lung disease causing chronic respiratory disability in majority of people. There is now strong scientific evidence to recommend the application of pulmonary rehabilitation programs in chronic lung diseases. MATERIALS AND METHODS: 28 patients of stable COPD were enrolled for this study. Patients were randomized into two groups, one group received pulmonary rehabilitation programme plus standard medical therapy (SMT) $(n=15)$ designated as case and other that received standard medical therapy alone $(\mathrm{n}=13)$, designated as control. OBSERVATIONS AND RESULT: There was no significant difference in changes in Forced Vital Capacity (FVC), Forced expiratory volume in $1^{\text {st }}$ second $\left(\mathrm{FEV}_{1}\right)$ and percentage predicted $\mathrm{FEV}_{1} / \mathrm{FVC}$ (\% predicted) after the pulmonary rehabilitation programme, when compared between cases and controls. However after pulmonary rehabilitation programme the change in Borg's scale score for post-exercise dyspnoea, when compared between cases and controls showed statistically significant difference. Also the St. George's Respiratory Questionnaire (SGRQ)-symptoms score in patients receiving pulmonary rehabilitation programmes plus Standard Medical treatment, when compared after rehabilitation programme was significantly greater than patients receiving only standard medical treatment. CONCLUSION: Pulmonary rehabilitation programme improved exercise capacity, symptoms and health related quality of life without any significant change in pulmonary functions. So, comprehensive pulmonary rehabilitation programme should be considered for overall management of chronic obstructive pulmonary disease along with recommended pharmacological treatment.

KEY WORDS: Chronic Obstructive Pulmonary Disease, Pulmonary Rehabilitation, Borg's scale

INTRODUCTION: Chronic obstructive pulmonary disease (COPD) causes chronic respiratory disability in majority of people. Surveys of people with chronic lung disease by British Lung Foundation suggest that $90 \%$ of chronic lung disease is due to chronic airflow obstruction 1 . Exercise intolerance a characteristic and troubling manifestation of this disease, is because of peripheral muscle weakness, de-conditioning, impaired gas exchange in lung and peripheral muscle. 
Years ago, patients with chronic pulmonary disease were given a standard prescription for rest and avoidance of exercise. Well in the 1960s, the stress imposed by exercise was considered deleterious to people with pulmonary disorders. They were treated as invalids, sometimes being referred to as "respiratory cripples". A 1964 study by Pierce et al. provided the impetus to change direction in the treatment of pulmonary dysfunction ${ }^{2}$.

COPD is now the most common chronic lung disease and the major impetus for the development of pulmonary rehabilitation programs. Initially, neglected because it failed to change pulmonary mechanics, pulmonary rehabilitation is now an integral part of the management of all patients with persistent symptoms reaching Global Initiative for Chronic Obstructive Lung Disease (GOLD) stages II, III and IV³. Pharmacological therapy alone does not optimize and have limited role in improving exercise tolerance, dyspnea and quality of life in these patients.

There is now strong scientific evidence to recommend the application of pulmonary rehabilitation programs in chronic lung disease $3,4,5$. The principal goals of pulmonary rehabilitation is to reduce symptoms, decrease disability and handicap, increase participation in physical and social activities (functional independence) and to improve the overall quality of life for individuals with chronic respiratory diseases while diminishing the health care burden ${ }^{5,6}$. These goals are achieved through several process including exercise training, patient and family education, instruction in respiratory and chest physiotherapy techniques, dietetics, occupational therapy, energy conservation and work simplification techniques, psychosocial and behavioral intervention ${ }^{6,7}$. Benefits of pulmonary rehabilitation includes improvement in exercise performance (Evidence A), reduction in perceived intensity of breathlessness (Evidence A), improvement in health related quality of life (Evidence $A$ ), reduction in health care utilization (Evidence B), improve survival (Evidence C) $3,5,8$.

The most recent definition ${ }^{6}$ of pulmonary rehabilitation is a "multidisciplinary program of care for patients with chronic respiratory impairments that is individually tailored and designed to optimize physical and social performance and autonomy".

With this background this study was designed to evaluate the beneficial effect of pulmonary rehabilitation in stable patients of chronic obstructive pulmonary disease in terms of preservation of lung functions and improvement in quality of life.

MATERIALS AND METHODS: The study is designed as a prospective, randomized controlled, single centered study in patients of stable COPD of stage II, III and IV, having functional limitation, between pulmonary rehabilitation plus standard medical treatment (SMT) and standard medical treatment (SMT) alone.

Inclusion criteria: Cases of chronic obstructive pulmonary disease $\leq 75$ years of age based on clinical history, physical examination, chest radiographs and confirmed by spirometry were choosen. Only moderate to very severe cases of COPD reaching GOLD stages II, III and IV and had not experienced an exacerbation or been hospitalized in previous month or had not experienced any change in sputum production or colour, breathlessness and cough which is beyond from normal day to day variation that did not lead to change in medication.

Exclusion criteria: Patients with age $>75$ years, acute exacerbation in the previous month, active pulmonary tuberculosis, bone and joint disease, corpulmonale, diabetes mellitus, history of recent surgery (major) or trauma (major), history of recurrent hemoptysis, past history of pulmonary tuberculosis, hypertension, ischemic heart disease, neuromuscular 
disorder, oxygen saturation $<88 \%$ at rest (room air), any co-existing medical or surgical cause and unwilling to participate in the study were excluded.

All stable patients of COPD that fulfilled the inclusion criteria $(n=28)$ were enrolled for this study. They were randomized using random number tables in to two groups, one that received pulmonary rehabilitation programme plus SMT $(n=15)$ designated as case and other that received SMT $(n=13)$, designated as control.

Baseline assessment of all the patients in both limbs were evaluated for pulmonary function, exercise capacity, symptoms, nutritional status, various clinicophysiological parameters and health related quality of life at baseline i.e. before entering into the study by various standard tools like Pulse Oximetery, Spirometery, Modified Borg's Scale ,Six Minute Walk Test (6 MWT) and St. George's Respiratory Questionnaire (SGRQ). After the baseline assessment of all patients enrolled for this study, only those patients who were in pulmonary rehabilitation group were trained in various aspects of pulmonary rehabilitation programmes.

The comprehensive pulmonary rehabilitation programme given to these patients was formulated according to the various recommendations given by standard evidence based guidelines. Duration of this rehabilitation programme was 12 weeks. It included flexibility and stretching exercises, level surface walking, graded stair climbing exercise, toe raising and squats for physical reconditioning; pursed lip breathing, diaphragmatic breathing for breathing retraining; adequate hydration, steam inhalation, chest percussion, postural drainage and control coughing and huffing for bronchial hygiene; health education, dietetics and psychosocial support.

Data were analyzed using statistical software package SPSS version 2.0. A difference between two values was considered to be significant only if 'p' value was found to be $<0.05 . \chi^{2}$ statistical tests were used to test the association between two or more variables in case of frequency distribution. Fisher's exact p-value was as and when required.

Two sample t-tests were used to compare the means between 2 independent groups whereas paired t-test was used to see the difference at an interval of 12 weeks from baseline values, if data was normally distributed. If data was not found to be normally distributed, a nonparametric equivalent of two-sample t-test, Mann Whitney test was used to test the level of significance between two values.

OBSERVATIONS AND RESULT: Patients in the pulmonary rehabilitation plus SMT group (cases) showed (Mean \pm SD) decline of $0.12 \pm 0.43 \mathrm{~L}$ after the pulmonary rehabilitation programme in pre-bronchodilator FVC. Similarly, patient in SMT only group (controls) showed a (Mean \pm SD) decline of $0.09 \pm 0.38 \mathrm{~L}$ in pre-bronchodilator FVC after the study. This change in FVC (pre-bronchodilator) after the pulmonary rehabilitation programme from baseline, were not statistically significant $(\mathrm{p}=0.8139)$ between the cases and controls. There was a decline of (Mean \pm SD) $0.72 \pm 0.08$ liters in FVC in patients of pulmonary rehabilitation + SMT group and a similar decline of (Mean \pm SD) $0.31 \pm 0.11$ was also observed in patients of control group after the study period, in post-bronchodilator FVC. No statistically significant difference $(p=0.8050)$ was found in the change between cases and controls regarding change in post-bronchodilator FVC.

There was a decline in FEV1 from baseline (Mean \pm SD) $0.11 \pm 0.42 \mathrm{~L}$ in pulmonary rehabilitation plus SMT group in pre-bronchodilator $\mathrm{FEV}_{1}$. A similar decline of $(\mathrm{Mean} \pm \mathrm{SD})$ $0.03 \pm 0.22 \mathrm{~L}$ in control group was also found in pre-bronchodilator $\mathrm{FEV}_{1}$. The change in prebronchodilator $\mathrm{FEV}_{1}$ after pulmonary rehabilitation programme, between the both groups was not statistically significant $(\mathrm{p}=0.6994)$. 
Percent predicted of post bronchodilator $\mathrm{FEV}_{1}$ increased (Mean \pm SD) $0.21 \pm 10.69(\%)$ after pulmonary rehabilitation programme in pulmonary rehabilitation group, while a decrease (Mean+SD) 1.91+4.52 was noted in control group after the study. These changes in Percent predicted of post-bronchodilator $\mathrm{FEV}_{1}$ from baseline, between cases and controls after pulmonary rehabilitation programme showed no significance $(p=0.7374)$.

Percent predicted pre-bronchodilator $\mathrm{FEV}_{1} / \mathrm{FVC}$ ratio increased by (Mean $\pm \mathrm{SD}$ ) $2.5 \pm 9.12 \%$ in pulmonary rehabilitation group after the programme but a decline of (Mean \pm SD) $0.53 \pm 3.83 \%$ was found in control group after the same time period. These changes in $\%$ predicted $\mathrm{FEV}_{1} / \mathrm{FVC}$ (Pre-bronchodilator) after the pulmonary rehabilitation programme were not found statistically significant $(\mathrm{p}=0.2779)$, when compared between the cases and controls. Percent predicted post-bronchodilator $\mathrm{FEV}_{1} / \mathrm{FVC}$ increased by (Mean $\pm \mathrm{SD}$ ) $2.82 \pm 8.14 \%$ in Pulmonary rehabilitation + SMT group (cases) and a slight increase was also observed $($ Mean \pm SD) $0.31 \pm 4.17$ in standard medical treatment (SMT) alone group (controls) after pulmonary rehabilitation programme. There was no significant difference $(p=0.6039)$ in changes in \% predicted $\mathrm{FEV}_{1} / \mathrm{FVC}$ (Post-bronchodilator) after the pulmonary rehabilitation programme, when compared between cases and controls.

There was a decline from base line $($ Mean \pm SD) $1.17 \pm 0.23$ in pulmonary rehabilitation group in dyspnoea (at rest) score after the rehabilitation programme. Similarly, the patients in the control group also showed a decline of (Mean \pm SD) $0.12 \pm 0.28$ in Borg's scale score for Dyspnoea (at rest) after the study. The change in dyspnoea (at rest) score, from baseline when compared between cases and control showed significant $(p=0.0091)$ difference after pulmonary rehabilitation programmes.

A decrease in Borg's scale score for post-exercise dyspnoea (Mean \pm SD) $(2.25 \pm 1.47)$ was observed in pulmonary rehabilitation group, while increase in Borg's score (Mean \pm SD) $0.25 \pm 1.86$ from baseline was noted in control group after the pulmonary rehabilitation programme. After pulmonary rehabilitation programme the change in Borg's scale score for post-exercise dyspnoea, when compared between cases and controls showed statistically significant difference $(\mathrm{p}=0.0008)$

The SGRQ-symptoms score improved (Mean \pm SD) $19.14 \pm 6.60$ in patients receiving pulmonary rehabilitation programme, as compared to patients in control group (Mean \pm SD) $3.00 \pm 4.13$ who were receiving standard medical treatment (SMT) only. The SGRQ-symptoms score in patients receiving pulmonary rehabilitation programmes + Standard Medical treatment, when compared after rehabilitation programme was significantly greater $(p=0.001)$ than patients receiving only standard medical treatment.

Patients receiving pulmonary rehabilitation programme along with SMT showed more improvement (Mean \pm SD)13.92 \pm 5.51 in SGRQ-activity score as compared to patients in control group (Mean \pm SD) $0.68 \pm 1.73$, after pulmonary rehabilitation programme. Patients in pulmonary rehabilitation group showed significant improvement $(\mathrm{p}=0.000)$ in SGRQ-activity score, in comparison to patient in control group after the rehabilitation programme.

Improvement (Mean \pm SD) $11.74 \pm 6.85$ in SGRQ-impact score was observed in pulmonary rehabilitation programme along with SMT (cases) group after pulmonary rehabilitation programme. Improvement (Mean \pm SD) $0.25 \pm 0.87$ in SGRQ-impact score was also present in control group. There was statistically significant difference in the change of SGRQ-impact score $(p=0.000)$, when compared between the two groups after the pulmonary rehabilitation programme. Thus, SGRQ-impact score improved more in patients of pulmonary rehabilitation + Standard Medical Treatment group. 
The improvement in SGRQ total score from baseline after pulmonary rehabilitation was (Mean \pm SD) $13.71 \pm 4.97$ in intervention (PR+SMT) group, a improvement of (Mean \pm SD) $0.75 \pm 1.77$ was also observed in total score of SGRQ in control group.

DISCUSSION: Chronic obstructive pulmonary disease is a common disabling condition. It gradually impairs a patient's overall physical ability because of exertional breathlessness and peripheral muscle weakness. Loss of physical capacity and adverse psychological effect of COPD contribute greatly to morbidity. There is limited role of pharmacotherapy in improving symptoms and physical capacity of these patients. People suffering from severe form of this disease usually spent their remaining years of life in bed and have impaired health related quality of life.

Not much work has been carried out regarding pulmonary rehabilitation in COPD patient in India while the prevalence of the disease is high and increasing continuously. In view of this scenario, the present study was carried out to evaluate the beneficial effect of pulmonary rehabilitation in stable COPD patients.

A total of 28 patients were included in this study, of which 15 were randomly enrolled in pulmonary rehabilitation plus SMT group and 13 were randomly enrolled in control group receiving only conventional medical treatment. All the 28 patients were receiving similar possible medical therapy according to their stage, at least 2 months before the study and throughout the study. None had experienced any exacerbation in previous one month and all were stable on the present medical treatment. All 28 patients had documented that they had functional limitation secondary to dyspnoea for one or more daily activity.

In the present study, there was no significant change in absolute value of prebronchodilator FVC $(\mathrm{p}=0.8139)$, post-bronchodilator FVC $(\mathrm{p}=0.8050)$, pre-bronchodilator $\mathrm{FEV}_{1}$ $(\mathrm{p}=0.6994)$ and post-bronchodilator $\mathrm{FEV}_{1}(\mathrm{p}=0.6632)$ between both groups. No significant change was also observed in percent predicted of post-bronchodilator $\mathrm{FEV}_{1}, \%$ predicted of $\mathrm{FEV}_{1} / \mathrm{FVC}$ (pre) and \% predicted of post-bronchodilator $\mathrm{FEV}_{1} / \mathrm{FVC}$ between the both groups after pulmonary rehabilitation programme. This is in concordance with Virendra Singh et al. $(2001)^{9}$ who also did not found any significant change in percent predicted of postbronchodilator $\mathrm{FEV}_{1}$ in their study of domiciliary pulmonary rehabilitation programme for COPD patient. However Guell R et al. (2000) ${ }^{10}$ found that there was a significant improvement in FVC in actively rehabilitated patients, but $\mathrm{FEV}_{1}$ remain unchanged in both groups. As FVC is dependent on muscular effort where the $\mathrm{FEV}_{1}$ is not, such change could explain the finding of the present study as compared to other previous study.

In present study, (Mean \pm SD) differences among various scores of SGRQ for quality of life between pulmonary rehabilitation plus SMT (cases) and SMT only (Control) group were: symptoms score $19.14 \pm 6.60$ vs. $3.00 \pm 4.13$, activity score $13.92 \pm 5.51$ vs $0.68 \pm 1.73$, impact score $11.74 \pm 6.85$ vs. $0.25 \pm 0.87$ and total SGRQ score $13.71 \pm 4.97$ vs $0.75 \pm 1.77$. These differences between cases and control group were statistically significant for symptom score $(p=0.001)$, activity score $(p=0.000)$, impact score $(p=0.000)$ and total SGRQ score $(p=0.000)$ which reflected a significant improvement in health related quality of life. Finnerty J.P. et al. (2001)11 found SGRQ score in the active group was 59.9 (SE, 2.0) at study entry $(n=36), 47.4$ (SE, 2.3) at 12 weeks $(n=32)$, and 50.6 (SE, 2.5) at 24 weeks $(n=24)$. The SGRQ in the control group was 59.3 (SE, 2.5) at study entry and did not change significantly over 24 weeks. There was a significant improvement between the two groups at 12 weeks $(\mathrm{p}<0.001)$. Man WD et al. $(2004)^{12}$ also found significant improvement in SGRQ total score $(-12.7,-5.0$ to $-20.3, \mathrm{P}=0.002)$. 
Similarly Boxall AM et al. (2005) ${ }^{13}$ found significant improvement in St. George's respiratory questionnaire total score $(\mathrm{P}=.020)$, and impact sub-score $(\mathrm{P}=.024)$.

In present study there was an improvement in Borg's scale score for dyspnoea (at rest) $1.17 \pm 0.27$ units (Mean \pm SD) (the decrease in Borg's scale score signify improvement) in patients of intervention group, while improvement $0.12 \pm 0.28$ units(Mean \pm SD) was also observed in control group after the study period, showed significant difference $(\mathrm{p}=0.0091)$. Borg's scale score for post exercise (6 MWT) dyspnoea improved 2.25 \pm 1.47 units (Mean \pm SD) in Intervention group, significantly ( $\mathrm{p}=0.0008)$, when compared with the deterioration $0.25 \pm 1.87(\mathrm{Mean} \pm \mathrm{SD}$ ) in control group after 12 weeks.

Reardon J et al. (1994) ${ }^{14}$ found that dyspnoea (at rest) were no significant difference in treatment and control group. But at maximum workload $\mathrm{D}_{\max } \%$, (dyspnoea at maximum workload, expressed as the $\%$ of Borg's scale line length) decrease from $74.4 \pm 18.9 \%$ at baseline to $50.5 \pm 23.2 \%$ in treatment group $(\mathrm{p}=0.015)$ when compared to control group. The baseline to repeat change in $D_{\max }$ was significantly different between the two groups $(-23.9 \pm 25.3 \%$ in treatment group Vs. 7.4 \pm 19.4 percent in control group, $\mathrm{p}=0.006)$. López Varela M.V. et al. (2006) ${ }^{15}$ also found improvement in mean Borg's score 2.2(1.37) before rehabilitation and 1.47(1.37) after rehabilitation. Like other previous studies on pulmonary rehabilitation the present study revealed that a comprehensive pulmonary rehabilitation alleviates the distressing symptoms of COPD.

CONCLUSION: Stable patients of COPD with functional limitation are potential candidates for pulmonary rehabilitation programme. Physical training, exercise for bronchial hygiene, breathing retaining, health education, dietetics and psychosocial support should be incorporated in an effective comprehensive pulmonary rehabilitation programme for COPD. Duration of 12 weeks is sufficient for an effective pulmonary rehabilitation programme.

The present study concluded that, pulmonary rehabilitation programme improved exercise capacity, symptoms and health related quality of life without any significant change in pulmonary functions. So, comprehensive pulmonary rehabilitation programme should be considered for overall management of chronic obstructive pulmonary disease along with recommended pharmacological treatment.

\section{REFERENCES:}

1. Hartbest K, McNeil S, Trelfalle et al. British lung foundation survey of respiratory health care provision in greater London. Thorax 2000;54:(Suppl3)A 43.

2. Pierce A et al. Response to exercise training in patients with emphysema. Arch Int Med 1964;114:28.

3. Global strategy for the diagnosis, management and presentation of chronic obstructive pulmonary disease. NHLBI/WHO Global Initiative for Chronic Obstructive Lung Disease: GOLD UPDATED 2011 Executive Summary (www.goldcopd.com).

4. Denis EO, Donnell et al. Canadian thoracic society recommendations for management of COPD-2003. Can. Resp. J 2003;10:Suppl. A.

5. BTS statement, pulmonary rehabilitation. Thorax (Indian Edition) 2002;1:399-406.

6. American thoracic society, pulmonary rehabilitation 1999, Am J Respi. Crit. Care, Med 1999;150:1666-82.

7. Clark CJ. Setting up a pulmonary rehabilitation programme. Thorax 1994;49,270-278. 
8. Pulmonary rehabilitation, joint ACCPI/AACVPPP evidence based guidelines. Chest 1997;112:1363-96.

9. Singh Virendra, Khandelwal DC, Khandelwal R and Abosaria S. Pulmonary rehabilitation in patients with chronic obstructive pulmonary disease. Indian J. Chest Dis Allied Sci 2002;45:13-17.

10. Guell R, Casan P, Belda J, Gyalt Gil, Snchis J et al. A longterm effects of outpatient rehabilitation of COPD. Chest 2000;117:976-83.

11. James Patrick Finnerty, Iain Keeping, Irene Bullough, Julie Jones. The Effectiveness of Outpatient Pulmonary Rehabilitation in Chronic Lung Disease. Chest 2001; 119(6):170510.

12. Man WD, Polkey MI, Donaldson N, Gray BJ, Moxham J. Community Pulmonary rehabilitation after hospitalization for acute exacerbations of chronic obstructive pulmonary disease: randomized controlled study. BMJ 2004;329:1209-13.

13. Boxall AM, Barclay L, Sayers A, Caplan GA. Managing chronic obstructive pulmonary disease in the community. A randomized controlled trial of home-based pulmonary rehabilitation for elderly housebound patients. J Cardiopulm Rehabil 2005;25 (6):37885.

14. Reardon J, Award E, Normandin E et al. The effect of comprehensive outpatient pulmonary rehabilitation on dyspnea. Chest 1994;105:1046-52.

15. María Victorina López Varela, TurquesaAnido, and MaríaLarrosa Functional Status and Survival in Patients with Chronic Obstructive Pulmonary disease following Pulmonary Rehabilitation Arch Bronconeumol. 2006;42(9):434-9.

Table-1: Modified Borg's Scale Score for Dyspnoea, at baseline and after pulmonary rehabilitation programme

\begin{tabular}{|l|l|l|l|l|}
\hline \multirow{2}{*}{ Group } & \multicolumn{2}{|l|}{$\begin{array}{l}\text { Modified Borg's Scale score for Dyspnoea } \\
\text { at rest (Mean+SD) }\end{array}$} & $\begin{array}{l}\text { Modified Borg's Scale score for } \\
\text { post-exercise } \\
\text { (Mean } \pm \text { SD) }\end{array}$ \\
\cline { 2 - 5 } & At Base line & $\begin{array}{l}\text { After Pulmonary } \\
\text { Rehabilitation } \\
\text { Programme }\end{array}$ & At Base line & $\begin{array}{l}\text { After Pulmonary } \\
\text { Rehabilitation } \\
\text { Programme }\end{array}$ \\
\hline $\begin{array}{l}\text { Cases } \\
(\mathrm{n}=14)\end{array}$ & $1.46 \pm 0.94$ & $0.28 \pm 0.25$ & $3.42 \pm 1.39$ & $1.17 \pm 1.03$ \\
\hline $\begin{array}{l}\text { Controls } \\
(\mathrm{n}=12)\end{array}$ & $1.33 \pm 1.02$ & $1.20 \pm 0.86$ & $4.54 \pm 2.49$ & $4.79 \pm 2.65$ \\
\hline
\end{tabular}

Table-2: St. George respiratory questionnaire (SGRQ)-Total score for quality of life at baseline and after pulmonary rehabilitation programme

\begin{tabular}{|l|l|l|}
\hline \multirow{2}{*}{ Group } & \multicolumn{2}{|l|}{ SGRQ-Total score (Mean \pm SD) } \\
\cline { 2 - 3 } & At Base line & $\begin{array}{l}\text { After Pulmonary Rehabilitation } \\
\text { Programme }\end{array}$ \\
\hline Cases $(\mathrm{n}=14)$ & $54.00 \pm 8.41$ & $40.29 \pm 7.37$ \\
\hline Controls $(\mathrm{n}=12)$ & $56.00 \pm 8.90$ & $55.25 \pm 8.69$ \\
\hline
\end{tabular}


Fig.1: Various Domains of SGRQ scores comparison at baseline and after PRP

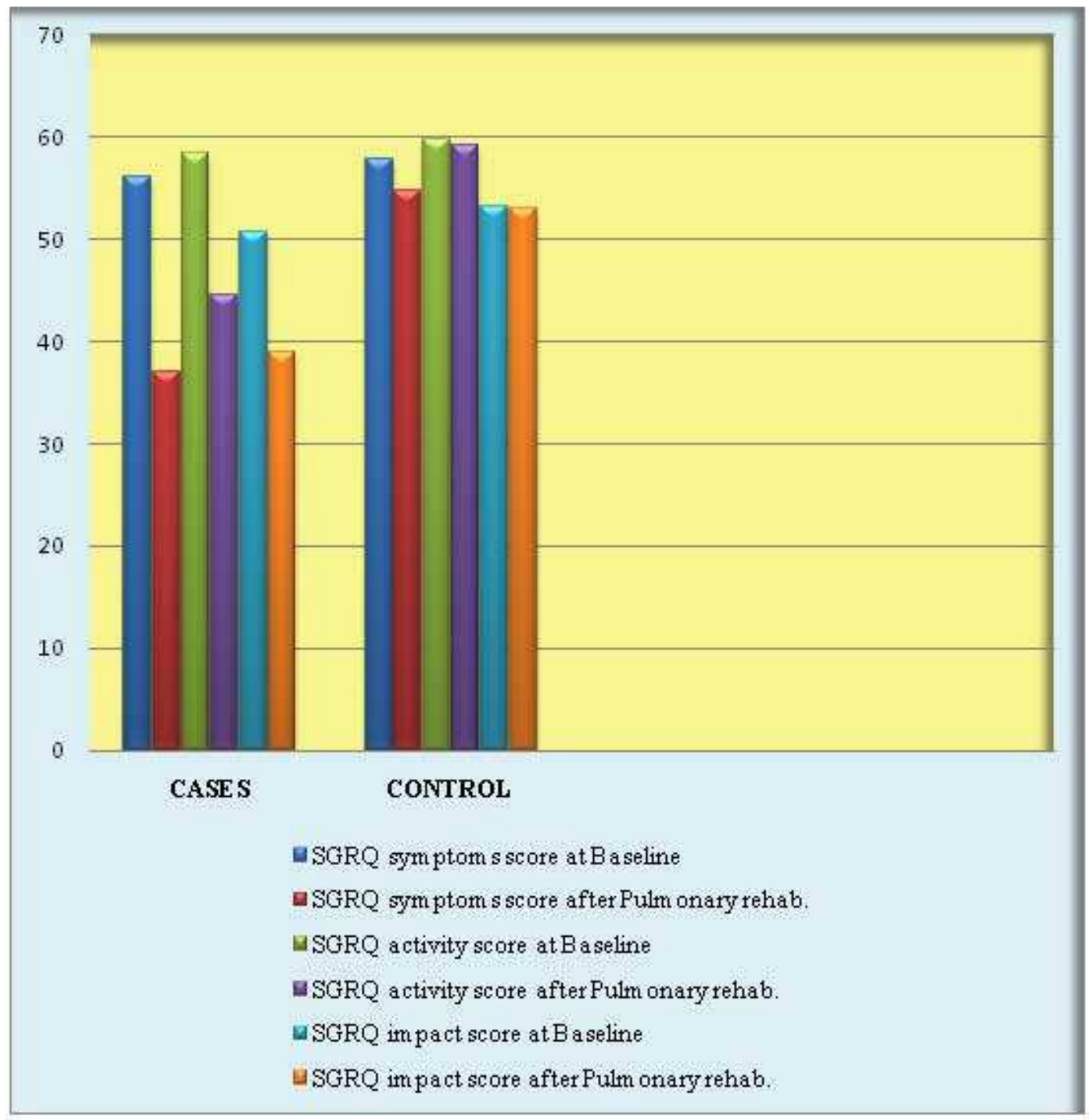

